\title{
What Is Going on in the Minds of Translators? A Review of Studies on Translation Process
}

\author{
WANG Bo \\ The Hong Kong Polytechnic University, \\ Kowloon, Hong Kong
}

\author{
MA Yuan-yi \\ Guangdong Institute of Technology, \\ Zhuhai, China
}

\begin{abstract}
Border areas have provided significant new research questions as well as fruitful insights and hypotheses. The cognitive and neuropsychologic study of translation process is a good example of this kind. This paper has surveyed various researches on translation process. Studies related to "the black box of translation" are divided into two categories, i.e., studies adopting think-aloud protocols, and studies from the physiology and neuroscientific perspectives. It has been noted that those studies on translation process have made some progress in the past years. Firstly, the participants have undergone a change from language learners to professional translators or interpreters. Secondly, the purposes of the studies have a tendency of gradually becoming specific. Thirdly, more rigorous methodologies have been developed, with more and more new technological approaches being applied.

Keywords: translation process, cognitive, think-aloud protocols, physiology, neuroscientific
\end{abstract}

\section{Introduction}

As Chesterman (2007) indicates, border areas have provided significant new research questions as well as fruitful insights and hypotheses. Consciousness or the cognitive and neuropsychologic study of translation process is a good example of this kind. After the prominence of linguistic and cultural approaches of translation studies, the cognitive paradigm was in full swing during the 1990s, whereas the focus of research has shifted from translation product to translation process.

There has been a long history for the studies on translation process. As Jääskeläinen (1998) suggests, "interest in the 'black box' of translation, i.e., the thought processes which take place when someone is translating a text, is probably as old as translating itself" (p. 265). As early as the 1960s, scholars on translation have already put forward various models on translation process (e.g., Hönig \& Kussmaul, 1982; Nida, 1969). However, these theories have never adopted any experimental method. According to Toury (1995), those researches "are all applicable in retrospect only" (p. 233). As LI indicates $(2005,2008,2011)$, due to the restriction of techniques and methods, translation process has never been fully explored until the 1980s. From the 1980s onwards, there has been a growing amount of research in this area. O'Brien (2013) attributes this to the development as well as the increased accessibility of different methods and tools for measuring the cognitive

WANG Bo, DALS candidate, Faculty of Humanities, The Hong Kong Polytechnic University. MA Yuan-yi, lecturer, Department of English, Guangdong Institute of Technology. 
aspects of the translation task. This paper attempts to review the existing studies on translation process from the following two perspectives, viz. studies adopting think-aloud protocols, and studies from the physiology and neuroscientific perspectives.

\section{Studies Adopting Think-Aloud Protocols}

The method of think-aloud protocols is borrowed from psychology, which serves as a methodology for eliciting verbal reports as a valid source on thinking (Jääskeläinen, 1998). By adopting think-aloud protocols in translation, researchers first need to ask a translator to translate a text. The translator then has to verbalize his or her thoughts as much as possible. The performances of the participants are recorded by equipments, while the retrieved data are later transcribed for further analysis. Studies adopting think-aloud protocols have different concentrations, and here the authors have sorted them into four categories, i.e., studies on translation strategy, translation unit, and translation brief.

\section{Studies on Translation Strategy}

Studies on translation strategies have occupied the pivotal status of translation studies with think-aloud protocols (LI, 2005). Scholars have adopted a process-oriented and descriptive viewpoint. In accordance with Lörscher (1991), translation strategy is defined as "a potentially conscious procedure for the solution of a problem which an individual is faced with when translating a text segment from one language to another" (p. 76). The conscious procedure implies that only the problems confronted by translators during the translation process could be treated as problems, and translation strategies aim to solve those problems, thus challenging the traditional approaches towards translation strategies (e.g., Wilss, 1982; Königs, 1987).

Jääskeläinen (1993) defines translation strategy as a process in relation to goal-orientedness and subjective optimality. In other words, translators adopt strategies as a means to attain their outcome during the translation process. It is found that professional translators adopt global strategies that concentrate on the overall style of target text, while non-professional translators seem to be in favor of local strategies that focus on actual operation.

\section{Studies on Translation Unit}

Before the emergence of think-aloud protocols, translation unit has been defined from a linguistic perspective. An early treatment by Vinay and Darbelnet (1958) takes translation unit as "the smallest segment of the utterance whose signs are linked in such a way that they should not be translated individually" (p. 352). As this definition has merely emphasized on prescriptive translation, and overtly focused on source text, it has been much criticized during the past years (e.g., Laviosa, 1998). While in process-oriented translation studies, take cognitive translation studies for example, translation unit is viewed from a different perspective.

Think-aloud protocols have offered a possible solution to the study of translation unit (LI, 2005). Jääskeläinen (1993) considers translation unit as the attention unit used for analysis during the translation process. While applying think-aloud protocols, scholars have adopted a much flexible view towards translation unit. Emphasis has been given to the segments which have been fluently translated. The segments could be either long or short, and may also vary according to the difficulty of the target text and the translators' processing speed (e.g., Gerloff, 1987; Lörscher, 1991, 1993; Séguinot, 1996). 
It has been found that experienced translators tend to apply longer translation units. Lörscher $(1991,1993)$ observes that language learners concentrate on words, while professional translators may either take phrases, sentences, or whole paragraphs as their translation units. Meanwhile, though emphasis is given to larger units, experienced translators would not neglect the processing of smaller units as well. Séguinot (1996) even suggests that professional translators take sentence groups as a reference system, without deliberate concentration on the equivalence between words or phrases. In comparison to the traditional viewpoints on translation units, studies adopting think-aloud protocols have offered a brand-new perspective. It is believed that translators do not work consistently on the pre-designed translation units during the process. In fact, the translation units they relied on are dynamic rather than static. Adjustments are made according to the actual situation whenever possible.

\section{Studies on Translation Brief}

Studies adopting think-aloud protocols also take the external conditions during the translation process into consideration. Cohen (1984) assumes that the degree of external intervention may influence the participants' mental process. However, he does not relate those factors in detail. As for translation studies adopting think-aloud protocols, the external factors may include environment, use of dictionary, translators' psychological traits, and translation brief, etc..

Fraser $(1993,1996)$ defines translation brief as the consignor's specific demands to the target text. In Fraser's (1993) study, she analyzes the data produced by 12 community translators during the process of translating government documents. She finds that for some translators, though translation brief is never mentioned, they would still assume an imagined one and apply it to the whole translation process. In a later study, Fraser (2000) further demonstrates the significance of translation brief. While translating non-formulaic texts and non-technical texts, the translators involved would seek to translation brief to determine the style of the target text. In this way, translations could meet the acceptability criteria of target-language text. As for language learners, their cognitive and linguistic capabilities are still developing, they have less experience in translation evaluation, and their works would meet lexical or semantic acceptability criteria only.

\section{Studies From the Physiological and Neuroscientific Perspectives}

Due to the limitations of think-aloud protocols as well as the developments of science and technology, new approaches have been applied to the study of translation process, particularly those from neuropsychologic and cognitive sciences. Recent studies have become interdisciplinary and are closely intertwined with physiology and neurolinguistics. Advanced technologies that break the ground include eye tracking, electroencephalography (EEG) and functional magnetic resonance imaging (fMRI).

O'Brien $(2006,2008)$ adopts eye tracking method to measure the cognitive load in translation tasks with the help of translation memory tools. By comparing different translation memory match types, he attempts to prove that eye tracking is an effective methodology for researches on translation process.

Chang's (2009) study aims to test the validity of the Revised Hierarchical Model put forward by Kroll and Stewart (1994), which argues that the translation of single words into the second language is more cognitive demanding than that into the first language. He employs both eye-tracker and fMRI scanner to provide neurological and physiological evidences. Meanwhile, the applicability of adopting these two approaches in translation studies has also been tested. He selects novice translators and interpreters as his participants, and 
identifies their physiological reactions and brain activation patterns. His study has shed some light on translator or interpreter training, and could be helpful for developing software which stimulates brain activities so as to assist learners in acquiring language skills. As O'Brien (2013) comments, "this was an early-stage study which recorded fMRI measures while participants silently translated" (p. 9).

Moser-Mercer (2010) draws on neurophysiology to her study of the plasticity of the brain. She summarizes various studies (e.g., Bontempi, Laurent-Demir, Destrade, \& Jaffard, 1999; Golestani et al., 2006; Rinne et al., 2000) and assumes that "the brain is a plastic structure that will change in response to deliberate practice and the demands of skill acquisition on the way to the development of expertise" (Moser-Mercer, 2010, p. 282). She labels three components of human cognition that are significant to the process of interpreting, i.e., control functions, knowledge representation in long-term memory as well as processing in short-term working memory. It has thus been assumed that changes in cognitive processing could produce long-term changes inside the brain, which would be helpful to the explanation of the complicated process of translation and interpreting.

\section{Conclusion}

This paper provides a survey of studies on translation process, and demonstrates the interdisciplinary feature of translation studies. The cognitive dimension of translation studies focuses on cognitive processing, which has to be inferred from researcher's observation. The central issues in the studies include: decision-making processes, influential factors like translator's attitudes, professional experience, time allotted, routine or non-routine characteristic of the translation task, all of which Toury (1995) has termed as "translation act".

During the past years, studies on translation process have made some progress in different respects. Firstly, the participants have shifted from language learners to professional translators or interpreters. Secondly, the purposes of the studies have gradually becoming specific. Thirdly, more rigorous methodologies have been developed, with more and more new technological approaches being applied.

After reviewing several studies, some research gaps have also been identified. First, the relationship between the translation process and the translators' personality has seldom been studied. It is likely that personality type may have some effects on the translation strategies adopted (e.g., risk-averse or risk-taking strategies). Further, as Toury's (1991) question on the interferential effect of verbal protocols on translation remains unanswered, the methodological framework still needs development so as to give an objective and natural account of the translation process. In addition, since new technological approaches have already been successfully applied to the study of translation process, how to best integrate or modify those approaches thus deserves further attention.

\section{References}

Bontempi, B., Laurent-Demir, C., Destrade, C., \& Jaffard, R. (1999). Time-dependent reorganization of brain circuitry underlying long-term memory storage. Nature, 400(6745), 671-675.

Chang, C. Y. (2009). Testing applicability of eye-tracking and fMRI to translation and interpreting studies: An investigation into directionality (Unpublished doctoral dissertation). Imperial College, London.

Chesterman, A. (2007). Bridge concepts in translation sociology. In M. Wolf \& A. Fukari (Eds.), Constructing a sociology of translation (pp. 171-183). Amsterdam and Philadelphia: John Benjamins Publishing.

Cohen, A. (1984). Studying second-language learning strategies: How do we get the information? Applied Linguistics, 5(2), 101-112. 
Fraser, J. (1993). Public accounts: Using verbal protocols to investigate community translators. Applied Linguistics, 14(4), $352-343$. Fraser, J. (1996). The translator investigated: Learning from translation process analysis. The Translator, 1, 65-79.

Fraser, J. (2000). What do real translators do? Developing the use of TAPs from professional translators. In S. Tirkkonen-Condit \& R. Jääskeläinen (Eds.), Tapping and mapping the process of translation and interpreting: Outlooks on empirical research (pp. 111-120). Amsterdam: John Benjamins.

Gerloff, P. (1987). Identifying the unit of analysis in translation: Some uses of think-aloud protocol data. In C. Færch \& G. Kasper (Eds.), Introspection in second language research (pp. 135-158). Clevedon: Multilingual Matters.

Golestani, N., Alario, F., Meriaux, S., Le Bihan, D., Dehaene, S., \& Pallier, C. (2006). Syntax production in bilinguals. Neuropsychologia, 44(7), 1029-1040.

Hönig, H. G., \& Kussmaul, P. (1982). Strategie der Übersetzung: Ein Lehr-und Arbeitsbuch (Translation strategy: A learn-and-workbook). Tübingen: Gunter Narr.

Jääskeläinen, R. (1993). Investigating translation strategies. In S. Tirkkonen-Condit \& J. Laffling (Eds.), Recent trends in empirical translation research (pp. 99-120). Joensuu: University of Joensuu Faculty of Arts.

Jääskeläinen, R. (1998). Think-aloud protocols. In M. Baker (Ed.), Routledge encyclopaedia of translation studies (pp. 265-269). London: Routledge.

Königs, F. G. (1987). Was beim Übersetzen passiert (What happened in translation). Die Neueren Sprachen (The New Language), 2 , 162-185.

Kroll, J. F., \& Stewart, E. (1994). Category interference in translation and picture naming: Evidence for asymmetric connections between bilingual memory representations. Journal of Memory and Language, 33(2), 149-174.

Laviosa, S. (1998). Unit of translation. In M. Baker (Ed.), Routledge encyclopaedia of translation studies (pp. 286-288). London: Routledge.

LI, D. (2005). TAPs fanyi guocheng yanjiu ershi nian: Huigu yu zhanwang (Utilizing TAPs in the study of translation process since the 1980s: A retrospection). Chinese Translators Journal, 26(1), 29-34.

LI, D. (2008). Yousheng siweifa zai fanyi jiaoxue zhong de yunyong: TAPs fanyi yanjiu dui fanyi jiaoxue de qishi (Thinking aloud as a useful tool in translator training). Chinese Translators Journal, 29(6), 34-39.

LI, D. (2011). Think-aloud teaching in translation class: Implications from TAPs translation research. Perspectives: Studies in Translatology, 19(2), 109-122.

Lörscher, W. (1991). Translation performance, translation process, and translation strategies: A psycholinguistic investigation. Tübingen: Narr.

Lörscher, W. (1993). Translation process analysis. In Y. Gambier \& J. Tommola (Eds.), Translation and knowledge (pp. 195-212). Turku: Center for Translation and Interpreting.

Moser-Mercer, B. (2010). The search for neuro-physiological correlates of expertise in interpreting. In G. M. Shreve \& E. Angelone (Eds.), Translation and cognition (pp. 263-288). Amsterdam: John Benjamins.

Nida, E. A. (1969). Science of translation. Language, 45(3), 483-498.

O'Brien, S. (2006). Eye-tracking and translation memory matches. Perspectives: Studies in Translatology, 14(3), 185-205.

O'Brien, S. (2008). Processing fuzzy matches in translation memory tools: An eye-tracking analysis. Copenhagen Studies in Language, 36, 79-102.

O'Brien, S. (2013). The borrowers: Researching the cognitive aspects of translation. Target, 25(1), 5-17.

Rinne, J. O., Tommola, J., Laine, M., Krause, B. J., Schmidt, D., Kaasinen, V.,... \& Sunnari, M. (2000). The translating brain: Cerebral activation patterns during simultaneous interpreting. Neuroscience Letters, 294(2), 85-88.

Séguinot, C. (1996). Some thoughts about think-aloud protocols. Target, 8(1), 75-95.

Toury, G. (1991). Experimentation in translation studies: Prospects and some pitfalls. In S. Tirkkonen-Condit (Ed.), Empirical research on translation and intercultural studies (pp. 45-66). Tübingen: Gunter Narr.

Toury, G. (1995). Descriptive translation studies and beyond. Amsterdam: John Benjamins.

Vinay, J. P., \& Darbelnet, J. (1958). Stylistique compare du français et de l'anglais (Stylistic comparison between French and English). Paris: Didier.

Wilss, W. (1982). The science of translation: Problems and methods. Tübingen: Gunter Narr. 